\title{
Mesenchymal Stem Cells in Renal Function Recovery After Acute Kidney Injury: Use of a Differentiating Agent in a Rat Model
}

\author{
Gaetano La Manna, ${ }^{*} \dagger^{1}$ Francesca Bianchi, $\uparrow^{1}$ Maria Cappuccilli, $* \dagger$ \\ Giovanna Cenacchi, $\uparrow \S$ Lucia Tarantino, $\uparrow \S$ Gianandrea Pasquinelli, $\uparrow$ II Sabrina Valente,$\uparrow \mathbb{I}$ \\ Elena Della Bella, $* \dagger$ Silvia Cantoni, $\uparrow \neq$ Cavallini Claudia, $\uparrow \neq$ Flavia Neri, $\uparrow$ Matvey Tsivian, $\dagger$ \\ Bruno Nardo, $\dagger$ Carlo Ventura, $\$$ and Sergio Stefoni*
}

\begin{abstract}
*Department of Internal Medicine, Aging and Renal Disease-Section of Nephrology, University of Bologna, Bologna, Italy
$†$ Center for Applied Biomedical Research (CRBA), S. Orsola-Malpighi University Hospital, Bologna, Italy \$Laboratory of Molecular Biology and Stem Cell Engineering, Cardiovascular Department-National Institute of Biostructures and Biosystems, University of Bologna, Bologna, Italy

§Clinical Department of Radiological and Histocytopathological Sciences-Section of Anatomical Pathology, University of Bologna, Bologna, Italy

IClinical Department of Radiological and Histocytopathological Sciences-Section of Clinical Pathology, University of Bologna, Bologna, Italy
\end{abstract}

\begin{abstract}
Acute kidney injury (AKI) is a major health care condition with limited current treatment options. Within this context, stem cells may provide a clinical approach for AKI. Moreover, a synthetic compound previously developed, hyaluronan monoesters with butyric acid (HB), able to induce metanephric differentiation, formation of capillary-like structures, and secretion of angiogenic cytokines, was tested in vitro. Thereafter, we investigated the effects of human mesenchymal stem cells from fetal membranes (FMhMSCs), both treated and untreated with $\mathrm{HB}$, after induction of ischemic AKI in a rat model. At reperfusion following 45-min clamping of renal pedicles, each rat was randomly assigned to one of four groups: CTR, PBS, MSC, and MSC-HB. Renal function at 1, 3, 5, and 7 days was assessed. Histological samples were analyzed by light and electron microscopy and renal injury was graded. Cytokine analysis on serum samples was performed. FMhMSCs induced an accelerated renal functional recovery, demonstrated by biochemical parameters and confirmed by histology showing that histopathological alterations associated with ischemic injury were less severe in cell-treated kidneys. HB-treated rats showed a minor degree of inflammation, both at cytokine and TEM analyses. Better functional and morphological recovery were not associated to stem cells' regenerative processes, but possibly suggest paracrine effects on microenvironment that induce retrieval of renal damaged tissues. These results suggest that FMhMSCs could be useful in the treatment of AKI and the utilization of synthetic compounds could enhance the recovery induction ability of cells.
\end{abstract}

Key words: Stem cells; Acute kidney injury (AKI); Mesenchymal stem cells (MSCs); Renal function; Renal cell biology

\section{INTRODUCTION}

Acute kidney injury (AKI) represents an increasingly frequent clinical condition in the field of Nephrology and Intensive Care Units. Although treatment with novel drugs and advanced life support techniques have improved survival of patients with severe organ impairment (often characterized also by a multiorgan failure), AKI remains in any case a major public health burden and its incidence is growing over time. The incidence of AKI is variable relative to the population examined, up to 288 cases per 100,000 population and with an $11 \%$ yearly increase (43). Moreover, AKI is a prognostic factor statistically related to mortality, hospitalization duration, and quality of life. In particular, in-hospital mortality is very high, especially in patients who need renal replacement therapy, exceeding 50\% (20,27). Research is very active in defining standards and support technol-

Received November 3, 2009; final acceptance November 8, 2010. Online prepub date: November 19, 2010.

${ }^{1}$ These authors provided equal contribution to this work.

Address correspondence to Prof. Gaetano La Manna, Dipartimento di Medicina Interna, dell'Invecchiamento e Malattie Nefrologiche, c/o U.O. Nefrologia, Dialisi e Trapianto, Policlinico S. Orsola-Malpighi, via Massarenti 9, 40138 Bologna, Italy. Tel: 051-6364577; Fax: 051-6363720; E-mail: gaetano.lamanna@unibo.it 
ogies in order to prevent, diagnose, and treat AKI. A revolutionary strategy of intervention may be represented by the application of regenerative medicine.

In a probable future, stem cells may restore damaged organs in their complexity, but now they allow repairing a variety of injuries, mainly acting as "pharmacological" agents.

There are many articles showing how stem cells may interact with adult tissues. In particular, mesenchymal stem cells (MSCs) are well characterized, easily available, and have been extensively studied both in vitro and in vivo $(4,6,9,12,13,31-34,48,49)$. It has been demonstrated that MSCs are able to promote tissue repair in many experimental settings. Here we employed human MSCs to treat functional ischemia/reperfusion (I/R) injury in a wild-type rat model, in order to determine the ability of MSCs to repair a nonstructural damage. Furthermore, on the basis of encouraging experiences on heart models $(41,42)$, we employed MSCs treated with novel differentiating agents, such as monoesters of hyaluronan with butyric acid (HB), in order to verify whether MSC preconditioning could led to further enhancements in I/R functional recovery. Hyaluronic acid represents an efficient targeting system, because its receptor CD44 is expressed on a variety of cells and ligand-receptor interaction leads to complex internalization of transported molecules (18), such as butyric acid, a histone deacetylase inhibitor, which activates expression of several genes, including those responsible for growth control and cell differentiation (25).

The aim of the study was to observe the effects of administration of human MSCs on recovery of renal function following I/R damage in a rat model, confirming our observations by histology and electron microscopy. Additionally, an objective to accomplish was to detect and characterize possible positive effects induced by pretreatment of stem cells with novel differentiating agents.

\section{MATERIALS AND METHODS}

\section{Preliminary Studies and Transdifferentiation Procedure}

Cell Isolation. According to the policy approved by the local Ethical Committee, all tissue samples were obtained after informed consent. Term placentas collected from caesarian sections were rapidly rinsed in phosphate-buffered saline (PBS) containing penicillin and streptomycin and used immediately. Pieces from fetal membranes were minced and digested for $10 \mathrm{~min}$ in Dulbecco's modified Eagle's medium (DMEM) with $0.25 \%$ trypsin-EDTA, $10 \mathrm{U} / \mathrm{ml}$ DNaseI, and $0.1 \%$ collagenase (Sigma-Aldrich Co., St. Louis, MO). Tissues were pipetted vigorously up and down avoiding foam for $5 \mathrm{~min}$; larger pieces of tissue were allowed to settle under gravity for $5 \mathrm{~min}$. Each supernatant was transferred to a fresh tube, neutralized with fetal bovine serum (FBS), and then spun at $1500 \mathrm{rpm}$ for $10 \mathrm{~min}$. Each pellet was resuspended in $5 \mathrm{ml}$ of DMEM containing $20 \% \mathrm{FBS}, 10 \mathrm{U} / \mathrm{ml}$ penicillin, and $100 \mu \mathrm{g} / \mathrm{ml}$ streptomycin. Human mesenchymal stem cells from fetal membranes (FMhMSCs) were seeded into $25-\mathrm{cm}^{2}$ flasks and grown at $37^{\circ} \mathrm{C}$ in $5 \% \mathrm{CO}_{2}$. Nonadherent cells were removed after 1 week and medium (with $10 \%$ FBS) was changed subsequently every 4 days.

Flow Cytometry Analysis. The fibroblast-like cells obtained from fetal membrane cultures were harvested by treatment with $0.08 \%$ trypsin-EDTA and incubated with $1 \mu \mathrm{g} / 10^{6}$ cells antibodies conjugated with different fluorescent probes for $40 \mathrm{~min}$ at $4^{\circ} \mathrm{C}$ in the dark. The antibodies used were: CD105 (Chemicon International, Millipore, Billerica, MA), CD73, CD90, CD166, CD14, CD34, CD44, and CD45 (Becton Dickinson, Franklin Lakes, NJ). After washing with PBS, cells were analyzed on a flow cytometer (FACSAria, Becton Dickinson) by collecting 10,000 events and the data analyzed using the FACSDiva Software (Becton Dickinson).

Cytofluorimetric analysis of FMhMSCs confirmed a mesenchymal antigenic profile $\left(\mathrm{CD} 29^{+}, \mathrm{CD} 166^{+}, \mathrm{CD}^{+} 3^{+}\right.$, $\left.\mathrm{CD}^{+}{ }^{+}, \mathrm{CD}_{105^{+}}, \mathrm{CD} 44^{+}, \mathrm{CD} 34^{-}, \mathrm{CD} 45^{-}, \mathrm{CD}^{-}\right)$as shown in Table 1 , and the culture with specific media triggered the differentiation in osteocytes, adipocytes, and chondrocytes, demonstrating the mesenchymal nature of the isolated population. In particular, the presence of the receptor of hyaluronic acid CD44 in more than $98 \%$ of cells strengthens the rationale for the use of these esters.

Adipogenic Differentiation. To induce adipocyte differentiation, cells were cultured using Mesenchymal Stem Cell Adipogenesis Kit (Chemicon International) according to the manufacturer's instructions. The growth medium was replaced every 2-3 days. After 2-3

Table 1. Percentage of Antigen Expression in Human Mesenchymal Stem Cells From Fetal Membranes (FMhMSC)

\begin{tabular}{lc}
\hline Antigen & \% Positive FMhMSC \\
\hline CD73 & $95 \pm 4$ \\
CD105 & $96 \pm 3$ \\
CD29 & $98 \pm 1$ \\
CD166 & $95 \pm 2$ \\
CD44 & $\mathbf{9 8} \pm \mathbf{2}$ \\
CD14 & 0 \\
CD34 & 0 \\
CD45 & 0 \\
\hline
\end{tabular}

FMhMSCs are positive for CD73, CD105, CD29, CD166, and CD44 and negative for CD14, CD34, and CD45, typical markers of hematopoiesis. 
weeks of culture the cells contained neutral lipids in fat vacuoles; they were fixed in $10 \%$ formalin and stained with fresh oil red-O solution (Sigma-Aldrich Co.) (Fig. 1a).

Osteogenic Differentiation. Cells were cultured in DMEM supplemented with $10 \%$ FBS until they were 80-90\% confluent. To induce osteogenic differentiation cells were plated in osteogenesis induction medium (Mesenchymal Stem Cell Osteogenesis Kit, Chemicon International) and maintained for 14-17 days, replacing the medium every $2-3$ days, according to manufacturing instructions. To demonstrate osteogenic differentiation, the cultures were fixed and von Kossa stained (Fig. 1b).

Chondrogenic Differentiation. To induce chondrogenic differentiation, aliquots of $2.5 \times 10^{5}$ cells were pelleted in polypropylene conical tubes in differentiation basal medium-chondrogenic (Poietics, Lonza, Basel, Switzerland) supplemented with hMSC Chondrogenic Single Quotes (Poietics, Lonza) and transforming growth factor- $\beta 3$ (TGF- $\beta 3$; Lonza). This medium was replaced every 2 days for 3-4 weeks. Pellets were formalin-fixed, embedded in paraffin, examined morphologically, and immunostained for type II collagen (Chemicon International), using Vectastain elite ABC kit (Vector Laboratories, Burlingame, CA) (Fig. 1c).

Gene Expression. Cells were treated with $\mathrm{HB}$ or HBR (hyaluronan mixed esters of butyric and retinoic acid) at the concentrations of $1,1.5,2$, and $3 \mathrm{~g} / \mathrm{L}$ for 7 days.

Total RNA was isolated using TRIzol reagent (Invitrogen, Carlsbad, CA), following the manufacturer's instructions. For RT-PCR, cDNA was synthesized in a $21-\mu \mathrm{l}$ reaction volume with $2 \mu \mathrm{g}$ of total RNA and SuperScript II RT (Invitrogen). In order to assess mRNA expression of genes specific for the metanephric mesenchyme, 20 ng cDNA was used for real-time RT-PCR performed with a Lightcycler system (Roche Diagnostics, Basel, Switzerland) and with the SYBR Green fast start kit (Lightcycler ${ }^{\circledR}$ FastStart DNA MasterPLUS
Table 2. Primer Sequences for Real-Time PCR

\begin{tabular}{|c|c|c|}
\hline Gene & Sense & Primer Sequence \\
\hline SCD & $\begin{array}{l}\text { forward } \\
\text { reverse }\end{array}$ & $\begin{array}{l}5^{\prime} \text {-GGTTTCACTTGGAGCTGTG-3' } \\
5^{\prime} \text {-GCCATGCAATCAATGAAGAA-3' }\end{array}$ \\
\hline $\mathrm{CD} 24$ & $\begin{array}{l}\text { forward } \\
\text { reverse }\end{array}$ & $\begin{array}{l}\text { 5'-GCCAGTCTCTTCGTGGTCTC-3' } \\
\text { 5'-TGTTTTTCCTTGCCACATTG-3' }^{\prime}\end{array}$ \\
\hline Cadh11 & $\begin{array}{l}\text { forward } \\
\text { reverse }\end{array}$ & $\begin{array}{l}5^{\prime} \text {-ATCGTCATTCTCCTGGGTTG-3' } \\
5^{\prime} \text {-GCCACCACATAGAGGAAAGG-3' }\end{array}$ \\
\hline YWHAQ & $\begin{array}{l}\text { forward } \\
\text { reverse }\end{array}$ & $\begin{array}{l}\text { 5'-CTTTTGATGAGGCCATTGCT-3' } \\
\text { 5'-TCCTGCACTGTCTGATGTCC-3' }\end{array}$ \\
\hline RAR $\alpha$ & $\begin{array}{l}\text { forward } \\
\text { reverse }\end{array}$ & $\begin{array}{l}5^{\prime} \text {-GAGATGGATGATGCGGAGAC-3' } \\
5^{\prime} \text {-TCCGCACGTAGACCTTTAGC-3' }\end{array}$ \\
\hline EWSH & $\begin{array}{l}\text { forward } \\
\text { reverse }\end{array}$ & $\begin{array}{l}\text { 5'-CCTGGACAAGGAAACAGGAA-3' } \\
\text { 5'-TCCGAGCAAGGGAGACTTTA-3' }\end{array}$ \\
\hline
\end{tabular}

SCD, stearoyl CoA desaturase; Cadh1, cadherin 11; YWHAQ, 14-3-3 protein theta; RAR $\alpha$, retinoic acid receptor $\alpha$; EWSH, Ewing sarcoma homolog.

SYBR Green I, Roche Diagnostics). Primer sequences used for real-time PCR are reported in Table 2.

Amplification included initial denaturation at $95^{\circ} \mathrm{C}$ for $10 \mathrm{~min}, 45$ cycles of denaturation at $95^{\circ} \mathrm{C}$ for $10 \mathrm{~s}$, annealing at $55-65^{\circ} \mathrm{C}$ for $6-10 \mathrm{~s}$, and extension at $72^{\circ} \mathrm{C}$ for $10 \mathrm{~s}$ performed at a temperature transition rate of $20^{\circ} \mathrm{C} / \mathrm{s}$. Fluorescence was measured at the end of each extension step. Specificity of the product was determined by a melting curve analysis.

After treatment with the esters, we analyzed the transcription levels of genes expressed at the first stages of nephrogenic differentiation, at the level of metanephric mesenchyme. The results revealed that the use of HBR did not increase expression of the considered genes after 7 days of treatment (data not shown). This result was partially expected, because precedent experiments had shown a selected action of this ester to induce cardio- a)

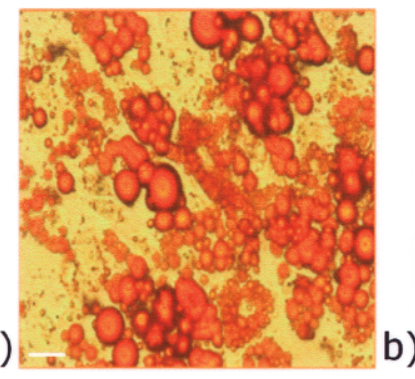

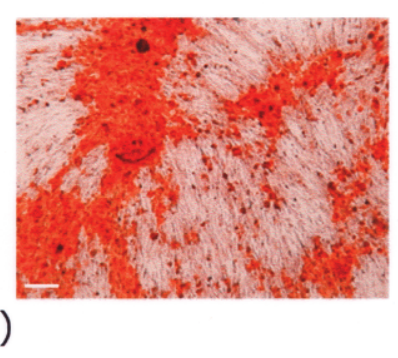

c)

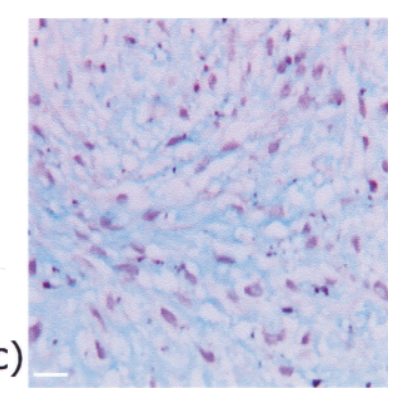

Figure 1. Induction of classical mesenchymal differentiation in human mesenchymal stem cells from fetal membranes (FMhMSCs). (a) Adipogenic differentiation; (b) osteogenic differentiation; (c) chondrogenic differentiation. Scale bars: $100 \mu \mathrm{m}$. 
genesis (41). We believed interesting in any case to test this molecule, because retinoic acid carries out an important role during renal development.

Conversely the treatment with $\mathrm{HB}$, with a peak at the concentration of $1 \mathrm{mg} / \mathrm{ml}$, increased significantly the transcription levels of all the genes analyzed ( $t$-test, $p<$ 0.05) (Fig. 2).

Endothelial Differentiation. Based on the fact that endothelial repair would represent an important goal in the prevention of chronic nephropathies, we tested the ability of FMhMSC to differentiate in capillary-like structures. Analysis of capillary formation was performed using Matrigel (ECM gel E1270, Sigma-Aldrich Co.), a semisolid medium. Fifty microliters of gel matrix solution, diluted 1:2 with DMEM, was applied to each well on a 96 -well plate and incubated for $1 \mathrm{~h}$ at $37^{\circ} \mathrm{C}$; $1 \times 10^{3}$ cells were then suspended in $50 \mu \mathrm{l}$ of DMEM, or HB $1 \mathrm{~g} / \mathrm{L}$ in DMEM, plated onto the gel matrix and incubated at $37^{\circ} \mathrm{C}$. Capillary-like structures were observed by optical microscopy after $2 \mathrm{~h}$ and at regular intervals during the following $24 \mathrm{~h}$.

Figure 3 shows the results of the Matrigel analysis. We observed that FMhMSCs treated with HB (1 mg/ $\mathrm{ml}$ ), were able to migrate and align themselves in Matrigel to form tubular-like structure already after 3-4 h (Fig. 3b), differently than untreated cells that exhibited capillary-like features only after $8 \mathrm{~h}$ and at remarkably lower extent (Fig. 3a).

Production of Angiogenic Cytokines. We tested the ability of FMhMSCs pretreated with HB to induce angiogenesis through secretion of cytokines.
We assessed the secretion of angiogenic cytokines [follistatin (FST), hepatocyte growth factor (HGF), granulocyte-colony stimulating factor (G-CSF), interleukin-8 (IL-8), leptin, CD31, platelet-derived growth factor (PDGF-BB), vascular endothelial growth factor (VEGF), and angiopoietin] with Bio-Plex Pro ${ }^{\mathrm{TM}}$ angiogenesis assay. This is a magnetic bead-based multiplex assay allowing the measurement of angiogenesis biomarkers in cell culture supernatant. Samples were prepared according to the manufacturer's instructions. Data from the reaction were then acquired using the Luminex system. The concentrations values were normalized on total protein amount.

Results are depicted in Figure 4. FST is an inhibitor of inflammation and a proangiogenic factor (19). It binds to activins, promoting tissue regeneration in the liver and kidney (24). FST levels (Fig. 4a) were significantly higher in the cells pretreated with HB, compared to control cells. This effect appeared at $48 \mathrm{~h}$ and maintained up to 14 days. The peak of release was observed at 7 days, followed by a decrease, probably due to a saturation effect or negative feedback. In any case, the treatment with $\mathrm{HB}$ led to a significant increase of release also at 14 days if compared to untreated cells.

HGF is one of the most important angiogenic and antiapoptotic cytokines (26). G-CSF is involved in the recruitment of granulocytes and stem cells from bone marrow (35). Platelet endothelial cell adhesion molecule-1 [PECAM-1 (CD31)] is a marker of differentiating endothelial cells, involved in inflammatory response, inducing tissue repair and vessel reconstruction (46). HB resulted in an increased of HGF (Fig. 4b), G-CSF (Fig.

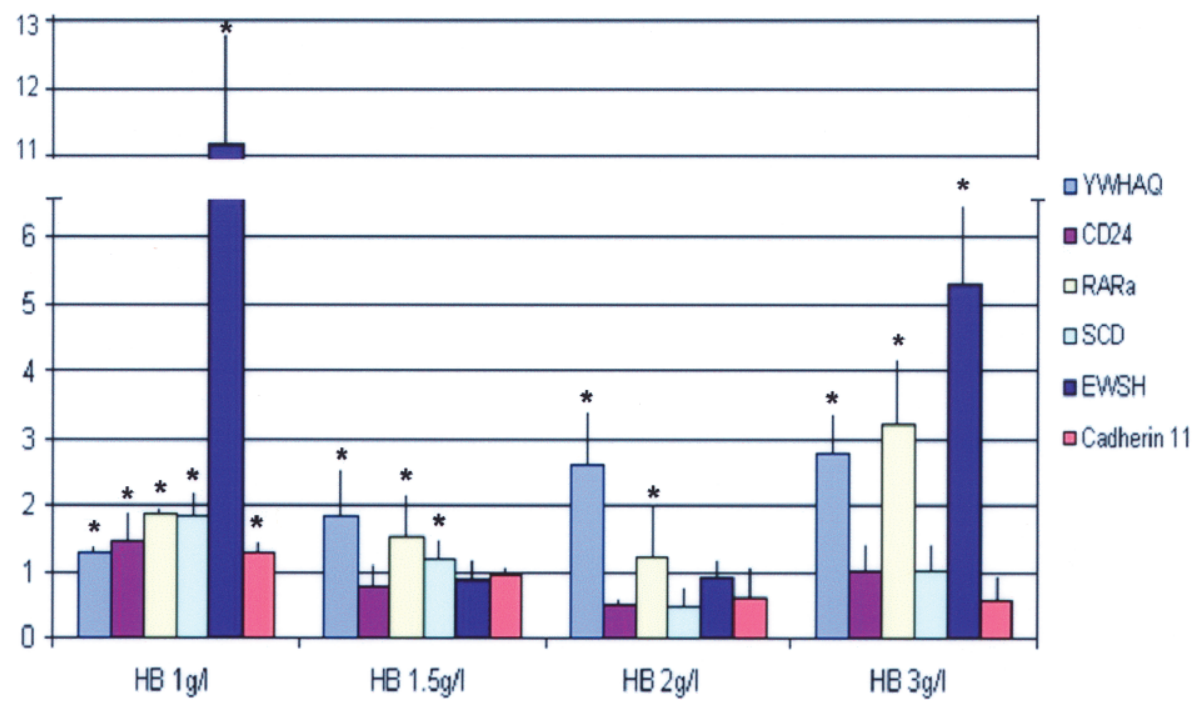

Figure 2. The treatment with HB (hyaluronan monoesters with butyric acid) $1 \mathrm{mg} / \mathrm{ml}$ is the most effective to increase the levels of expression of metanephric markers analyzed. 


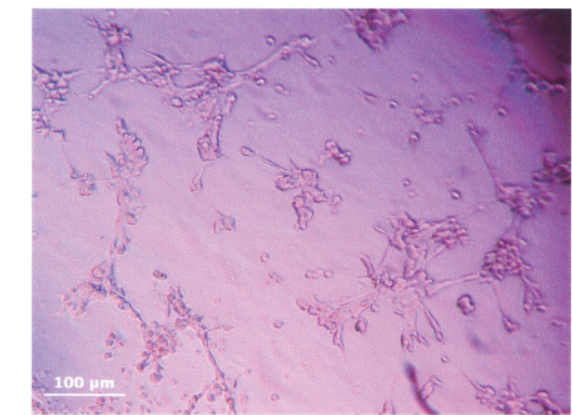

a)

b)

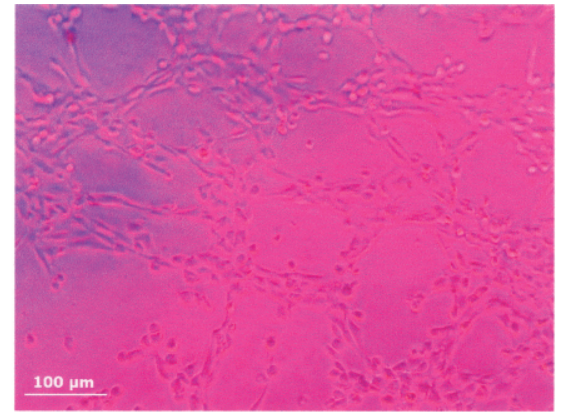

Figure 3. (a) Organization of untreated cells on capillary-like structures on semisolid medium after $8 \mathrm{~h}$. (b) Cells pretreated with $\mathrm{HB} 1 \mathrm{mg} / \mathrm{ml}$ show an increased capillary-like structure formation after $4 \mathrm{~h}$. Scale bars: $100 \mu \mathrm{m}$.

4c), and PECAM-1 (Fig. 4d) release, compared to the control, with a zenith at 14 days.

HB did not affect the secretion of IL-8 (Fig. 4f), a chemokine involved in inflammatory response and angiogenic activity in tumors.

PDGF-BB is secreted by platelets, it stimulates the growth of preexisting vessels, and together with TGF- $\beta$ it is implicated in repair of damaged vessels and generation of new ones (10). This cytokine (Fig. 4e) and VEGF (Fig. 4g) revealed a common pattern, with a rise in their release up to 14 days, but without any difference compared to the control.

Leptin is produced by adipose tissue and has an important role in angiogenesis process increasing the levels
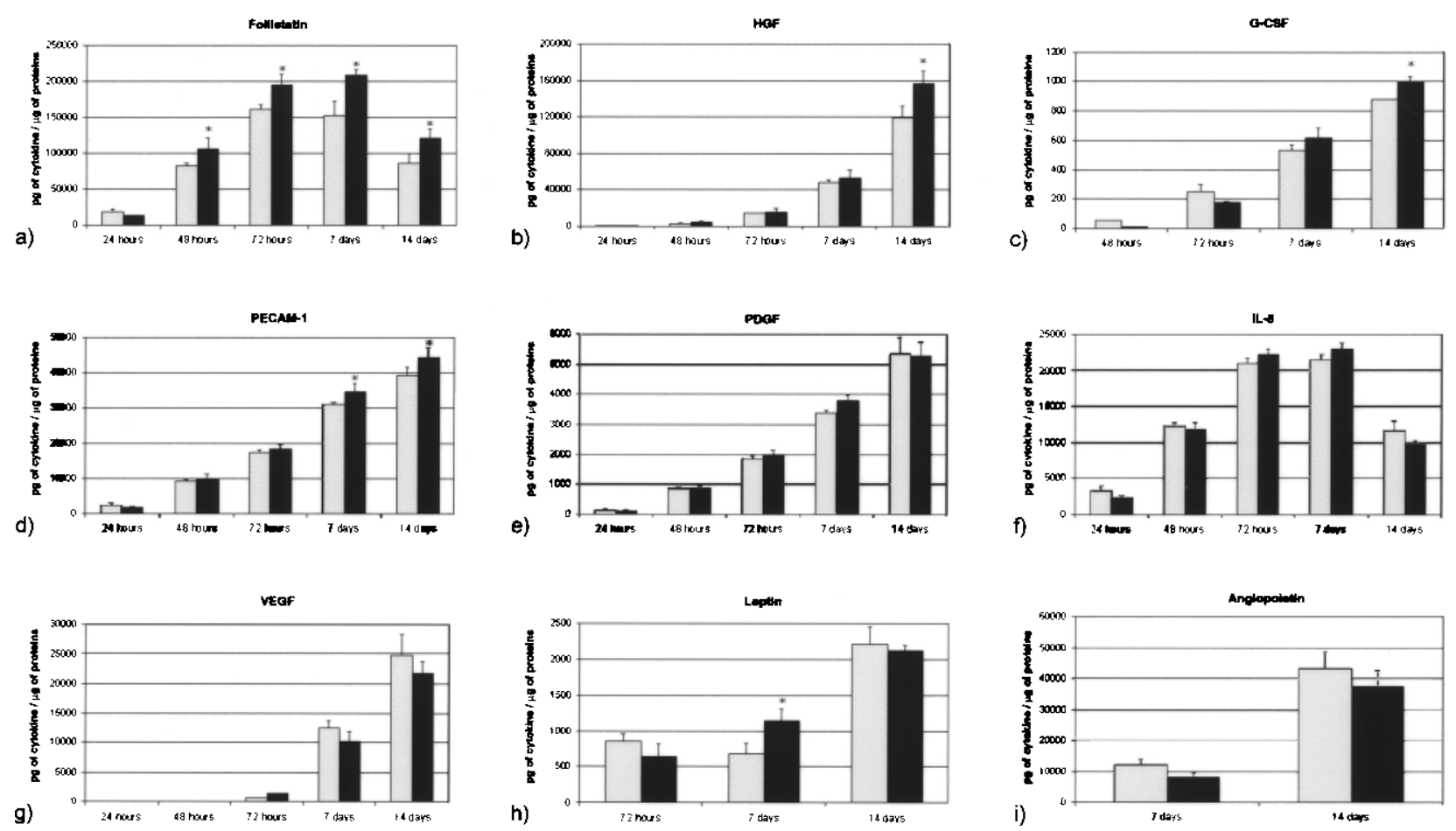

Figure 4. Analysis of secretion of angiogenic cytokines comparing FMhMSCs (light bars) and HB-treated FMhMSCs (black bars) up to 14 days. HB treatment was performed at a concentration of $1 \mathrm{~g} / \mathrm{L}$. (a) Follistatin (FST); b) hepatocyte growth factor (HGF); c) granulocyte-colony stimulating factor (G-CSF); d) platelet endothelial cell adhesion molecule-1 (PECAM-1 or CD31); e) plateletderived growth factor (PDGF); f) interleukin-8 (IL-8); g) vascular endothelial growth factor (VEGF); h) leptin; i) angiopoietin. Values are normalized to total protein amounts. ${ }^{*} p<0.05$. 
of VEGF (8). Angiopoietin is a growth factor able to promote angiogenesis and the formation of new blood vessels from preexisting ones (36). Both leptin (Fig. 4h) and angiopoietin (Fig. 4i) were not initially expressed by control or treated cells, but they were secreted at 7 days and $72 \mathrm{~h}$, respectively. The release of leptin was higher in cells treated with $\mathrm{HB}$ compared to control, at 7 days. We could not observe any difference in angiopoietin secretion.

The potentiality for nephrogenic transdifferentiation of cultured FMhMSCs after treatment with $\mathrm{HB}$ was also tested. We observed that treatment with $1 \mathrm{~g} / \mathrm{L}$ of $\mathrm{HB}$ induced the highest expression of genes specific for metanephric mesenchyme. Furthermore, cells showed the ability of forming capillary-like structures and enhanced secretion of the angiogenic cytokines considered, with elevated production of anti-inflammatory molecules (Fig. 4).

\section{Study Protocol}

Taken together, the preliminary results of the in vitro studies on HB-treated FMhMSCs suggest that the cells are able to express markers of nephrogenic differentiation and to form capillary-like structures: we then tested whether these cells could help tissue repair in a model of ischemic renal acute damage in wild-type rats.

Study Design. Twenty-four animals were followed to 7 days of survival. The animals were monitored in metabolic cages to monitor urine output. At days 1, 3, 5, and 7 (i.e., at sacrifice) urine and blood samples were collected and analyzed by standard laboratory methodologies. Urinary sodium, creatinine, and urea were determined and urine output was registered. Serum creatinine, urea, and sodium were measured. Creatinine clearance and fractional excretion of sodium were calculated using standard formulas. Both kidneys of each animal underwent histological evaluation with light microscopy to assess residual renal damage. To quantify the amount of damage we used an histological score proposed by Karpinski et al. (15) that takes glomerular, tubular, interstitial, and vascular components into account. Immunohistochemistry assays were performed with an anti-human mitochondria antibody (1:100, Chemicon International) to detect and localize the administered stem cells in the tissue.

An additional 12 animals were sacrificed at $24 \mathrm{~h}$ from reperfusion, in order to study premature response to damage. In these animals, equally randomly divided into the four treatment arms, blood samples were harvested preischemia and at 1, 6, and $24 \mathrm{~h}$ postischemia. At sacrifice kidneys were fractioned and prepared for histological and immunohistochemical analyses.

Surgical Procedure. All animal experiments were approved by Bioethics Committee of the University of
Bologna. Thirty-six male Sprague-Dawley rats (weighing 230-280 g) were used for this experiment. The animals were anesthetized with xylazine-tiletamine/zolazepam (Zoletil®, Virbac, Carros, France) and placed on a deltaphase heating pad (2Biol, Besozzo, Italy). The abdominal cavity was accessed transperitoneally through a midline xyfopubic incision to gain access to both kidneys. All animals underwent an ischemia-reperfusion damage by bilateral 45-min clamping of both renal pedicles. At reperfusion each animal was randomly assigned to one of four therapy groups: CTR - control group; PBS - administration of $0.15 \mathrm{ml}$ of PBS; MSC — administration of $1 \times 10^{6}$ FMhMSCs suspended in $0.15 \mathrm{ml}$ of PBS; MSC-HB - administration of $0.15 \mathrm{ml}$ suspension of $1 \times 10^{6}$ FMhMSCs pretreated with esters of hyaluronic and butyric acids ( $1 \mathrm{~g} / \mathrm{L}$ for 14 days). PBS and stem cells were injected directly into the cortex of only the left kidney. Right kidneys served as intragroup controls. Intraparenchymal administration was performed with a 24-gauge syringe in 4-5 injections of 0.03-0.05 $\mathrm{ml}$ each at different locations along the lateral aspect of the kidney.

Histology and Immunohistochemistry. After animals sacrifice, both kidneys were recovered and cut along median-longitudinal axis by a razor blade, fixed in $10 \%$ buffered formalin, and then embedded in paraffin; $4 \mu \mathrm{m}$ thick-sections were used for histological and immunohistochemical analysis. Each section was stained with hematoxylin and eosin and observed under a light microscope (LM) to quantify the amount of renal damage using the histological score proposed by Karpinski et al. (15).

Immunohistochemical study was performed with an anti-human mitochondria antibody (Chemicon International) and a non-biotin-amplified method (NovoLink ${ }^{\mathrm{TM}}$ Polymer Detection System, Novocastra Laboratories Ltd., Newcastle Upon Tyne, UK) to evaluate the presence of the administered stem cells in the tissue. Briefly, tissue sections were deparaffinated with xylene, rehydrated through a series of graded ethanol, and rinsed in distilled water. Antigens were unmasked with citrate buffer $\mathrm{pH} 6.0$, at $120^{\circ} \mathrm{C}, 1$ atm for $21 \mathrm{~min}$; endogenous peroxidase activity was neutralized using a Novocas$\operatorname{tra}^{\mathrm{TM}}$ Peroxidase Block and washed with Tris-buffered saline (TBS) $1 \times$. After that, the slides were incubated with Novocastra ${ }^{\mathrm{TM}}$ Protein Block for $5 \mathrm{~min}$ in a wet chamber to reduce the nonspecific binding of primary antibody and polymer reagent, and rinsed in TBS $1 \times$. The samples were subsequently incubated with the monoclonal antibodies (mAb) against anti-human mitochondria (1:100, Chemicon International) in PBS/1\% bovine serum albumin overnight at $4{ }^{\circ} \mathrm{C}$. After removal of unbound antibody, the slides were incubated for 30 
min at RT with Novocastra ${ }^{\mathrm{TM}}$ Post Primary Block to enhance penetration of the next polymer reagent, rinsed in TBS $1 \times$, and incubated with NovoLink ${ }^{\mathrm{TM}}$ Polymer for $30 \mathrm{~min}$ at RT. Further, the sections were exposed to the substrate/chromogen 3,3'-diaminobenzidine (DAB) prepared from Novocastra ${ }^{\mathrm{TM}}$ DAB Chromogen and NovoLink $^{\mathrm{TM}}$ DAB Substrate Buffer, rinsed in distilled water, and counterstained with Gill's hematoxylin. Subsequently, the samples were dehydrated, coverslipped, and viewed in a LM using the Image-Pro Plus ${ }^{\circledR}$ program. Negative control was obtained by omitting the primary $\mathrm{mAb}$.

Electron Microscopy. Specimens from each kidney were isolated from the cortical zone and fixed in glutaraldehyde $2.5 \%$ buffered in phosphate $0.1 \mathrm{M}$. After a postfixation in osmium tetroxide $1 \%$ in cacodylate buffer, the samples were dehydrated in graded ethanol and embedded in araldite. Ultrathin sections were counterstained in uranyl acetate and lead citrate before observation with a Philips 410 transmission electron microscope.

Cytokine Secretion Analysis. Blood samples were analyzed using Milliplex ${ }^{\mathrm{TM}}$ Map Rat Cytokine/Chemokine kit (Millipore) for the following cytokines: VEGF, granulocyte-macrophage colony stimulating factor (GM-CSF), interferon (IFN- $\gamma$ ), IL-1 $\alpha$, IL-1 $\beta$, IL-6, IFN-inducible protein-10 (IP-10), monocyte chemotactic protein-1 (MCP-1), and macrophage inflammatory protein- $1 \alpha$ (MIP-1 $\alpha$ ). Twenty-five microliters of sample per well was used. Cytokine analysis was performed following the manufacturer's instructions. Data were normalized to preischemia values.

Statistical Analysis. For in vitro study, statistical analysis was performed by using a one-way analysis of variance (ANOVA) and assuming a value of $p<0.05$ as the limit of significance. For in vivo study, data are expressed as means $(95 \% \mathrm{CI})$. Statistical analyses were performed for each time point with ANOVA on rank with Tukey post hoc test to evaluate for differences between renal score. A value of $p<0.05$ was assumed as the limit of significance. The statistical analyses were performed using SAS 9.1 software (SAS Institute Inc., Cary, NC).

\section{RESULTS}

\section{Recovery From Renal Damage}

Parameters describing renal function show that the peak of maximum functional decrease was at $24 \mathrm{~h}$ from induction of renal damage. This condition of AKI improved at 3 and 5 days and renal function returned to normal levels at 7 days from induction of ischemia-reperfusion $(\mathrm{I} / \mathrm{R})$ damage. Even though this trend was present in all four groups, there was evidence of significant dif- ferences in the timing of functional recovery. The two groups of rats treated with cells (MSC and MSC-HB), in particular, presented both a less severe AKI and a rapid course.

Results are summarized in Figure 5. Cell-treated groups had significantly lower serum creatinine (Fig. 5a) and urea levels (Fig. 5b) compared to the control groups CTR and PBS $(p<0.05)$. Creatinine clearance (Fig. 5c) on day 1 was markedly reduced in all groups, but at day 7 it returned to normal levels. MSC and MSC-HB groups recovered renal function, as expressed by creatinine clearance, significantly faster than the controls $(p<0.05)$

Fractional excretion of sodium (FE-Na) (Fig. 5d) peaked to abnormal levels at day 1 in control groups, while cell-treated rats maintained normal values, with differences characterized by a high statistical significance $(p<0.001)$. Measurements of FE-Na resulted within the normal levels in all groups. Serum sodium levels dropped significantly on day 1 in controls, while retaining normal levels in the treated groups $(p<0.05)$. On successive determinations natremia levels did not differ among the groups.

Urine osmolarity (Fig. 5e) was reduced on day 1 in all rats and rose from day 1 to day 7 with no significant differences between the groups. A trend toward a faster rise of osmolarity, however, could be observed in MSC and MSC-HB groups compared to the control groups. Urinary protein levels (Fig. 5f) were not significantly different among the groups.

\section{Histology and Immunohistochemistry}

As shown in Figure 6 (left panel), we observed different grades of renal injury at $24 \mathrm{~h}$ post-I/R with primarily tubular necrosis, epithelium loss, swelling, blebbing, and hyaline casts; tubular injury was usually patchy; glomeruli were characterized by minor damages. Kidney biopsies scored according to Karpinski et al. (15) showed moderately injured right and left organs in the CTR group (mean right + left score $2.17 \pm 0.68$ and mean left score $2.17 \pm 0.72$ ). Similar values were recorded for the PBS group with mean right + left score of $1.89 \pm 0.78$ and mean left score of $2.00 \pm 0.63$, while MSC (mean right + left score $1.22 \pm 0.67$ and mean left score $1.50 \pm 0.55$ ) and MSC-HB (mean right + left score $1.22 \pm 0.67$ and mean left score $1.17 \pm 0.75)$ had significantly lower scores when compared to CTR $(p<0.05)$. No significant differences were observed between right and left kidneys with a trend for lower injury scores in left (compared to right) kidneys of MSC-HB rats ( $p>$ 0.05). Major reparative phenomena were observed mostly at 7 days post-I/R, with large hyperchromatic nuclei, basophilic staining of tubular epithelial cytoplasm, and flattening of the tubular epithelial cells. Overall, tu- 

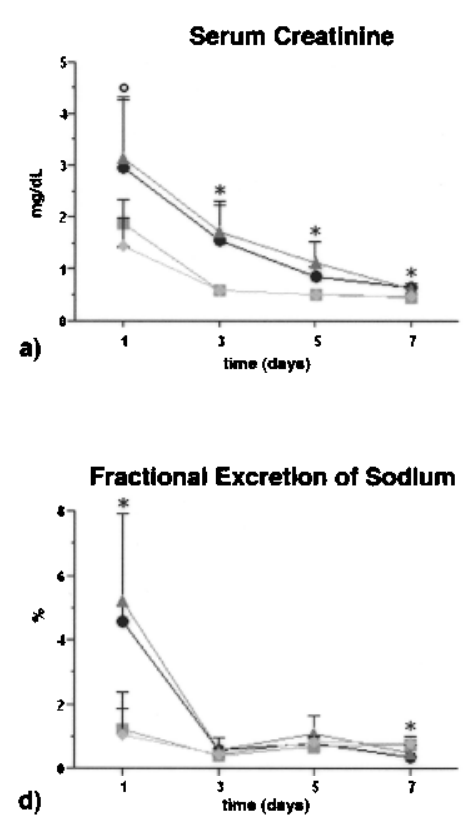
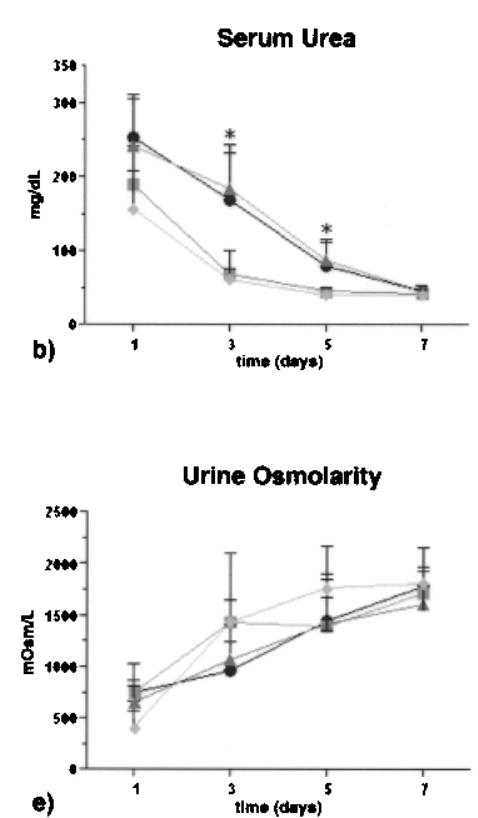
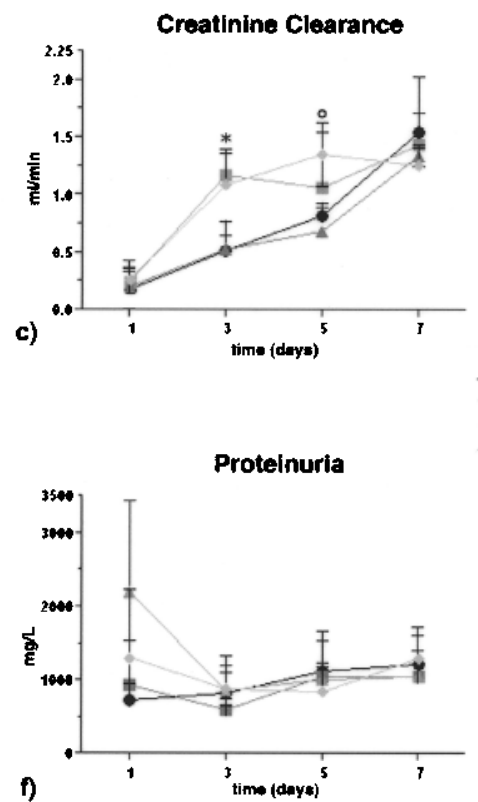

Figure 5. Analysis of biochemical parameters to evaluate renal function at 1, 3, 5, and 7 days post-I/R. (a) Serum creatinine, (b) serum urea, (c) creatinine clearance, (d) fractional excretion of sodium, (e) urine osmolarity, (f) proteinuria. $* p<0.05$, MSC and MSC-HB versus CTR and PBS. ${ }^{\circ} p<0.05$, MSC-HB only versus CTR and PBS. CTR, control group; PBS, PBS administration; MSC, administration of FMhMSCs; MSC-HB, administration of FMhMSCs pretreated with hyaluronic and butyric acids.

bular injury was minimal and a significantly decreased renal score was recorded both in right and left kidneys (CTR: mean right + left score $1.67 \pm 0.51$, mean left score $1.67 \pm 0.58$; PBS: mean right + left score $1.75 \pm$ 0.89 , mean left score $1.75 \pm 0.96$; MSC: mean right + left score $1.00 \pm 0.53$, mean left score $0.83 \pm 0.41$; MSC-HB: mean right + left score $0.75 \pm 0.46$, mean left score $0.67 \pm 0.51$ ). Representative images of histological analysis at 7 days are showed in Figure 6 (right panel). Again, the MSC and MSC-HB groups had significantly lower scores when compared with controls $(p<0.05)$ and left kidneys of the MSC-HB group had a substantially normal histological appearance.

In order to evaluate the presence of injected FMhMSCs within the kidneys, immunohistochemistry with human anti-mitochondria antibody was performed in right and left kidneys at 7 days postinjury. Immunostaining located human cells within the glomeruli, as well as in periglomerular and peritubular positions (Fig. 7). The distribution of positively stained cells was extremely patchy; no particular pattern of distribution could be observed: cortical and juxtaglomerular regions were irregularly stained both in left and right kidneys. Quantitative contribution of cell administration in renal parenchyma was modest; thus, no cell counts were performed.

\section{Transmission Electron Microscopy}

The electron microscopy analysis, as represented in Figure 8 , showed alterations visible both at tubular and glomerular levels. At $24 \mathrm{~h}$ from I/R injury, moderate to severe alterations were detected mainly in the tubular compartment: in particular CTR specimens were characterized by the presence of cell remnants in the tubular lumen and by several epithelial cells with degenerative alterations and loss of organelles. The glomerular compartment was well preserved from the ischemic insult. MSC rat samples revealed moderate degenerative aspects like those observed in the controls. The glomeruli were normal appearing. On the contrary, MSC-HB kidneys evidenced normal tubular epithelial cells together with presence of some mitotic figures (Fig. 9) that could be considered as a regenerative index. This result confirms a more rapid recovery in MSC-HB rats, as showed by histological sections.

At 7 days, CTR specimens exhibited degenerative changes of mitochondria characterized by dilation and loss of electrondense matrix, and cristae appeared fragmented. These alterations seem to be likely due to an osmotic balance dysregulation. No differences between CTR and PBS groups were detectable. The glomerular compartment featured moderate to severe alterations of podocytes and mesangial cells, characterized by picnotic nuclei. On the contrary, cell-treated kidneys had a normal appearing morphology at the ultrastructural level: tubular epithelial cells showed well-shaped and completely recovered mitochondria and glomerular cells showed normal submicroscopic morphology and architecture. 
24 hours



7 days

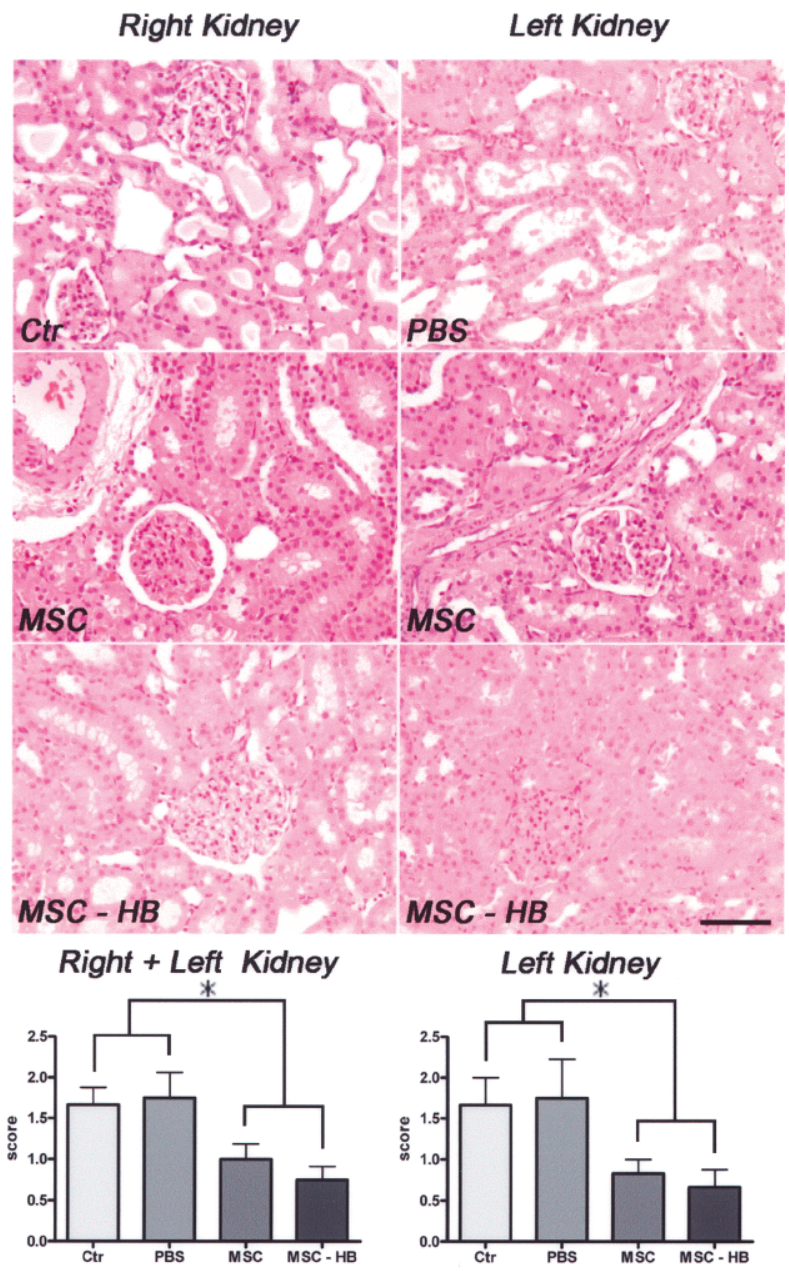

Figure 6. Representative images of kidney histology at $24 \mathrm{~h}$ (left panel) and 7 days (right panel) from I/R damage. At $24 \mathrm{~h}$ there was mainly a moderate degree of tubular injury, which was significantly ameliorated by kidney administration of MSC and HBtreated MSC. At 7 days tubular damage was decreased in all groups and particularly in the MSC-HB group, where an almost complete morphological recovery was seen. Hematoxylin and eosin stain; original magnification: 10×. The graphs represent mean histological score for each group in right + left and only left kidneys. MSC, human mesenchymal stem cells from fetal membranes; MSC-HB, MSC treated with hyaluronan monoesters and butyric acid compound. ${ }^{*} p<0.05$. Scale bars: $100 \mu \mathrm{m}$.

At 7 days, kidneys of rats in the CTR group, both left and right (Fig. 10a, b) displayed normal appearing capillaries lined with thin endothelial cells and exhibiting a smooth surface.

Left and right kidneys of MSC group animals (Fig. $10 \mathrm{c}, \mathrm{d})$ were characterized by vascular structures with a perivascular inflammatory infiltrate, constituted by some lymphocytes and monocytes. We observed endothelial cells with dispersed nuclear chromatin and electronlucent cytoplasm with few organelles.

In the MSC-HB group, both kidneys (Fig. 10e, f, left and right kidney, respectively) showed vascular structures with almost similar features as in the MSC-treated rats, but without the inflammatory infiltrate. Clear endo- thelial cells can be characterized by irregular surface with thin microvilli indicating activation of likely immature cells and neoformation of vessels. Figure 11 shows relevant details revealed by TEM analysis.

\section{Cytokine Analysis}

Results of cytokine analysis in serum of rats are summarized in Figure 12. Serum levels of IFN- $\gamma$ (Fig. 12a) were significantly lower $24 \mathrm{~h}$ after I/R in cell-treated rats, compared with controls. The secretion of IP-10 (Fig. 12b) at this time was significantly decreased in MSC group compared with CTR. At $24 \mathrm{~h}$ the levels of IL-1 $\beta$ (Fig. 12 c) were significantly lower in the MSCHB group and IL-1 $\alpha$ levels (Fig. 12d) were significantly 


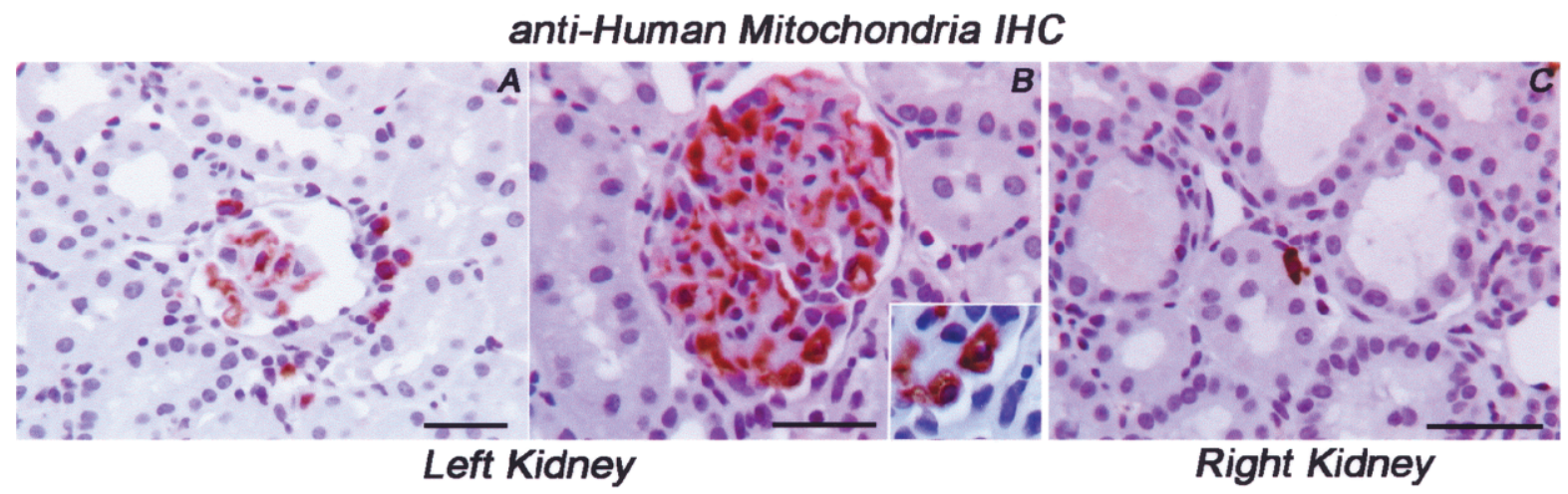

Figure 7. Immunohistochemical (IHC) detection of human MSC at 7 days post-I/R. IHC on left and rights kidneys demonstrates that in situ retention of MSC is minimal; MSC were seen in proximity of glomeruli (left panel), within glomeruli (central panel) and in peritubular stroma (right panel); the insert shows a couple of intraglomerular, pericapillary intensely stained MSC; an interesting finding was the MSC capability to target the contralateral right kidney from the site of injection. IHC with anti-human mitochondria monoclonal antibody. Nuclei are counterstained with hematoxylin. Original magnification: $25 \times$. Scale bars: $50 \mu \mathrm{m}$.

lower in MSC rats, compared to CTR. Serum levels of IL-6 (Fig. 12e) $1 \mathrm{~h}$ after I/R injury were significantly lower in cell-treated groups compared with PBS and in MSC-HB group compared with CTR. The secretion of this cytokine in the MSC group was maintained significantly lower compared with PBS after $6 \mathrm{~h}$. There was no significant difference between the four groups in serum levels of MIP-1 (Fig. 12f). Levels of MCP-1 (Fig. $12 \mathrm{~g}$ ) were significantly increased in MSC-HB group after 6 and $24 \mathrm{~h}$ compared to the PBS group, and after 1 and $6 \mathrm{~h}$ compared to the MSC group. Serum VEGF levels (Fig. 12h) at 1, 6, and $24 \mathrm{~h}$ were significantly higher in the MSC-HB group compared to CTR and PBS, and at 6 and $24 \mathrm{~h}$ compared to MSC.

\section{DISCUSSION}

The aim of our study was first to demonstrate that the administration of FMhMSCs in a rat model could be beneficial and lead to a faster recovery of reversible ischemic AKI. Second, we evaluated if the pretreatment of FMhMSCs with HB could further enhance the repair of kidney injury, given the property of HB to induce the secretion of cytokines and the differentiation of cells into metanephric progenitors or capillary-like structures.

Renal function trend was ameliorating during the 7 days after induction of $\mathrm{I} / \mathrm{R}$ injury in all groups of rats, both untreated and treated with FMhMSCs administration. Finally, at day 7, kidney function was completely restored in all groups; however, some differences emerged in relation to severity of renal injury and time of recovery.

Cell-treated rats showed a less severe AKI, as it could be evaluated 1 day after I/R injury by analyzing biochemical parameters, such as serum levels of creatinine and urea, creatinine clearance, and fractional excretion of sodium. Some of these parameters, which reflect the excretory function of the kidney, indicated a better condition in cell-treated rats. Serum creatinine levels (Fig. 5a) 1 day after treatment were lower in the MSC and MSC-HB groups, compared to controls (maximum value 2 vs. $3 \mathrm{mg} / \mathrm{dl}$ ). We also noticed that in cell-treated groups serum creatinine returned to normal levels already at day 3 , whereas control rats showed full restoration only at day 7 . The same trend could be observed for both serum urea levels (Fig. 5b) and creatinine clearance (Fig. 5c). Even FE-Na (Fig. 5d) was worst in untreated rats on day 1 , but it had a rapid recovery after 3 days from I/R damage, whereas in cell-treated groups it remained stable at low levels.

The clinical trend was confirmed by morphological studies: as expected, the histopathological alterations associated with I/R injuries were moderate in intensity, patchy in distribution, and mainly affecting the tubular compartment; glomeruli were almost undamaged if analyzed both at light and electron microscopy. Cell-treated kidneys showed a slightly better score, compared to controls. We noticed that the protective effect was acting early and it could be detected already at $24 \mathrm{~h}$ from damage induction, as there are signs of cell proliferation in renal tubular cells. Figure 9 demonstrates the presence of a mitosis that could be detected only in the MSC-HB group. It is important to highlight that the cell-treated kidneys had this significant lower extent of damage already at $24 \mathrm{~h}$ from induction of same degree of ischemia: we can hypothesize an important role of cell administration both in preventing I/R damage and promoting effective repair.

Seven days after I/R injury, there was a prompt recovery of tubular damage in all the groups considered; however, cell-treated kidneys healed more efficiently, 


\section{4 hours}

a)

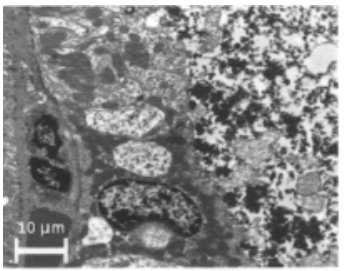

b)

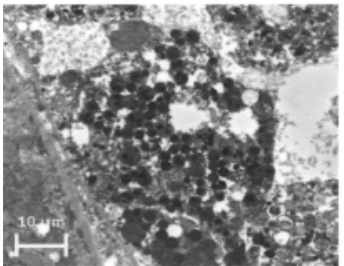

C)

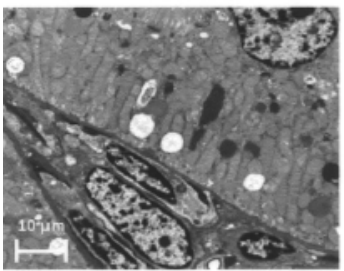

d)
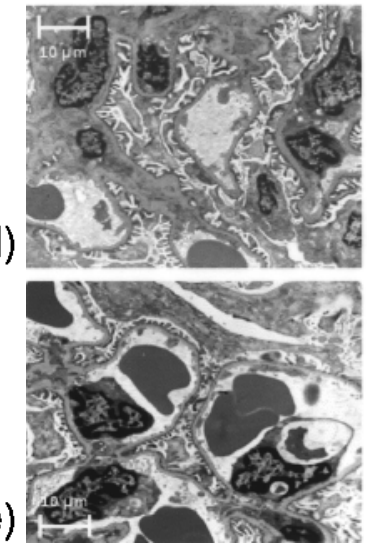

7 days



g)

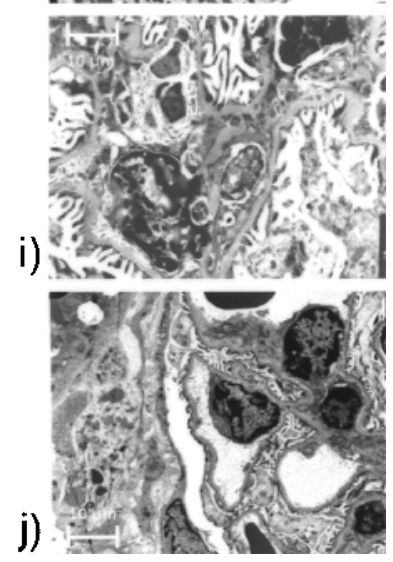

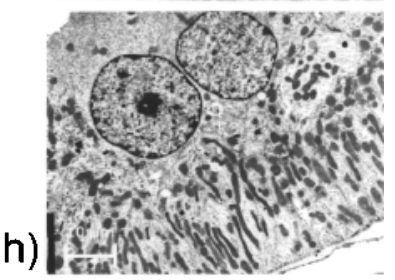

Figure 8. Transmission electron microscopy (TEM), 6,400×, scale bars: $10 \mu \mathrm{m}$. Kidneys of rats at $24 \mathrm{~h}$ (left panel, a-e) and 7 days (right panel, $f-j$ ) after ischemic damage. (a) CTR: tubular epithelial cells showing severe ischemic alterations and cell remnants in the luminal space. (b) MSC treated: few tubular epithelial cells with degenerative necrotic changes. (c) MSC-HB treated: Normal looking epithelial lining of tubular structures with a maintained architecture. (d) CTR: glomerular architecture seems to be unaffected by ischemic insult. (e) MSC-HB: the glomerulus shows a normal appearing organization, comparable to control kidney. (f) CTR: tubular epithelial cells showing submicroscopic alterations of mitochondria that appear swollen with fragmented cristae. (g) MSC treated: tubular epithelial cell with mild degenerative changes, mainly at the cell surface, with partial loss of microvilli. (h) MSC-HB treated: tubular epithelial cells feature normal appearing mitochondria with electrondense matrix and oriented cristae. (i) CTR: glomerular structures show a maintained architecture, but some mesangial cell and podocytes are characterized by degenerative changes. (j) MSC-HB treated: normal appearing glomerulus.

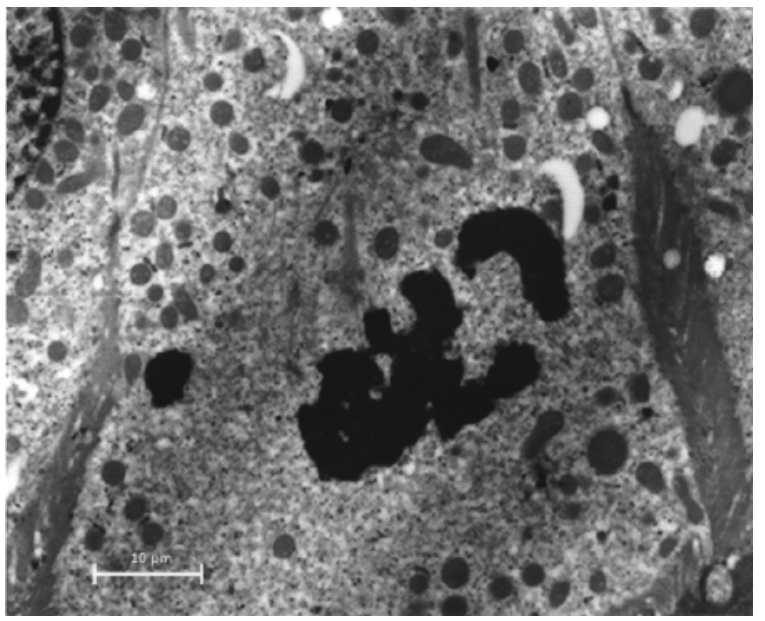

Figure 9. TEM, 6,400×, scale bar: $10 \mu \mathrm{m}$. MSC-HB-treated kidney $24 \mathrm{~h}$ postischemic damage. Few mitotic figures are visible among tubular epithelial cells.

particularly those injected with HB-treated FMhMSCs. In this group, light and electron microscopy revealed an almost complete structural recovery.

It has been demonstrated that MSCs from bone marrow can migrate to the site of kidney damage $(11,12)$ and contribute to injury recovery, especially in studies with models of sex-mismatched bone marrow or kidney transplantation $(28,29)$. However, migration and homing of MSCs are not yet fully understood even though the production of G-CSF from renal mTAL cells (52) after an ischemic damage and CD44-hyaluronic acid interaction (11) seems to play a significant role.

The mechanisms through which exogenous MSCs promote tissue repair are even more complex and for many aspects controversial. Some authors indicated that MSCs may act by transdifferentiation or cell fusion to replace the lost cells $(28,29)$, and this mechanism would reproduce the onset of natural strategies of repair. Other authors, instead, indicate that only a small number of cells can successfully engraft the organ and usually for a limited lapse of time $(3,7,12,37,38)$. This suggests that MSCs are unlikely involved in direct restoration of the organ, but cells prevalently act via paracrine mechanisms, stimulating repair from residual cells or even inducing proliferation and differentiation of organ-specific stem cells. Overall our results support this view; performing immunohistochemical analysis of the reperfused kidneys by antibody anti-human mitochondria, we found that there were just a few FMhMSCs engrafting the rat kidney, against the marked improvement in renal function that was observed, indicating that the administered stem cells do not contribute directly to tissue regeneration. Even though the absence of clear signs of regeneration seems to be in contradiction with other 

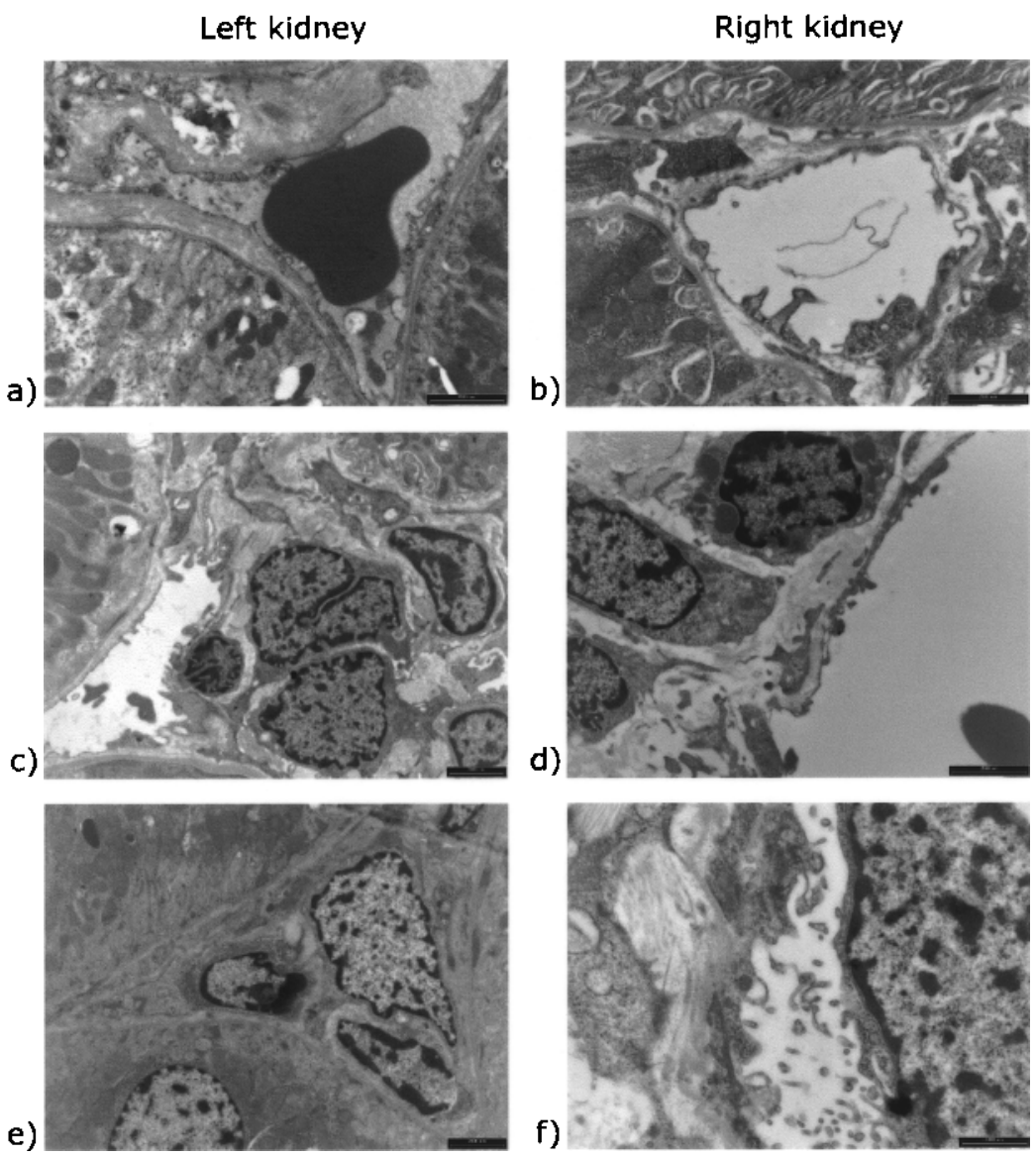

Figure 10. TEM, 6,400×, scale bars: $1 \mu \mathrm{m}$. Analysis of vasculature in different groups. (a) CTR group, left kidney; (b) CTR group, right kidney; (c) MSC group, left kidney; (d) MSC group, right kidney; (e) MSC-HB group, left kidney; (f) MSC-HB group, right kidney. In the CTR group (a, b) normal vessels is evidenced. In the MSC group (c, d) signs of vasculature regeneration is evidenced: the presence of dispersed nuclear chromatin and electron-lucent cytoplasm with few organelles is a sign of activation of endothelial cells. Moreover, some leukocytes infiltrating the tissue are observable. In the MSC-HB group (e, f) signs of neovascularization is still evident, but no inflammation is highlighted.

a)

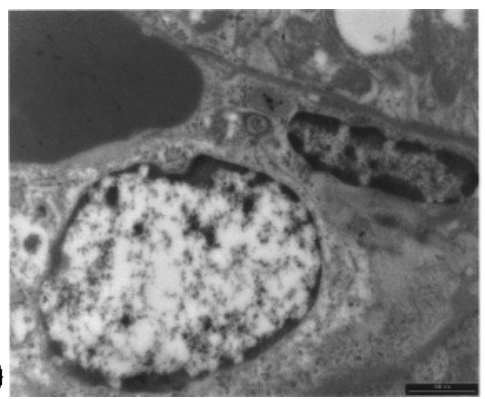

b)

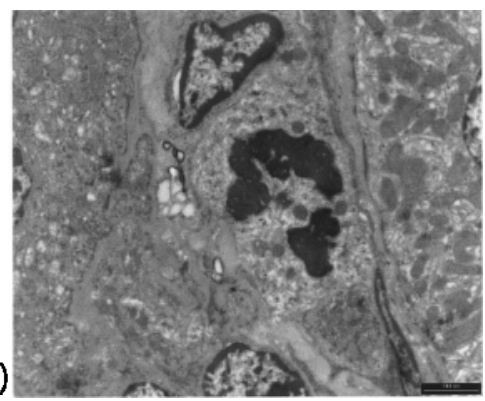

Figure 11. TEM, 6,400×, scale bars: $1 \mu \mathrm{m}$. Details of TEM analysis. (a) MSC group, an endothelial cell showing signs of activation. (b) MSC-HB group, a mitosis in an endothelial cell. 

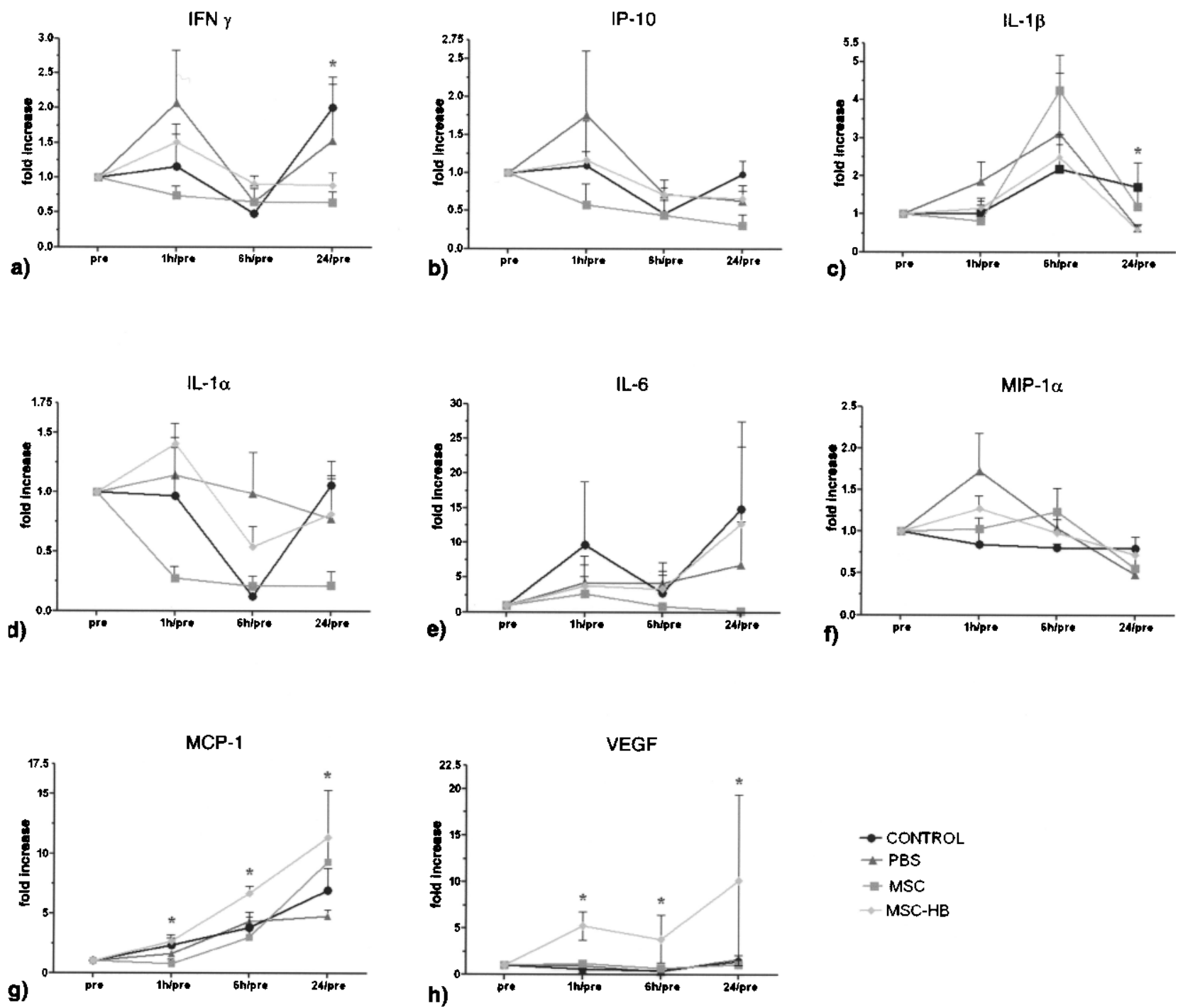

Figure 12. Cytokine levels in serum of rats preischemia, 1,6 , and $24 \mathrm{~h}$ after induction of $\mathrm{I} / \mathrm{R}$ damage. (a) Interferon (IFN- $\gamma$ ); b) IFN-inducible protein-10 (IP-10); c) IL-1 $\beta$; d) IL-1 $\alpha$; e) IL-6; f) macrophage inflammatory protein (MIP-1 $\alpha$ ); g) monocyte chemotactic protein (MCP-1); h) VEGF. Data are normalized to preischemia values. ${ }^{*} p<0.05$.

works, we observed both functional improvement and a better architectural tissue organization.

Cytokine serum assays suggest that in the present experimental setting FMhMSCs may restore renal function through a paracrine mechanism most likely involving also resident mesenchymal and tubular epithelial cells (12). Indeed, in cell-treated groups we detected lower levels of proinflammatory cytokines like IL- $1 \alpha$ and IL$1 \beta$, IL-6, IFN- $\gamma$, and IP10 than in controls, whereas levels of factors that tend to lower the inflammatory response, like MCP-1 and VEGF, were increased (Fig. 12). A positive influence on the balance between proand anti-inflammatory stimuli was particularly evident in MSC-HB-treated rats (Figs. 10, 12), which recovered promptly from AKI. After all, the anti-inflammatory effect of stem cells is well known, because there are several papers showing the ability of stem cells to reduce both cellular and humoral immune responses $(1,14,17$, 22,23). In particular, the administration of immature cells expressing major histocompatibility complex I (MHCI) at low levels without second signal receptors, such as costimulatory molecules CD40, CD80 and CD86, induces immune responses that support tolerance by Treg and Th 2 cell increase versus Th1 decrease, and the production of IL-4 and IL-10 anti-inflammatory cytokines (29).

Confirming evidence of anti-inflammatory effects derives also from several experiments on combined trans- 
plantation of solid organs and stem cells $(2,44,50,51,53)$. In this view, the use of MSCs in the treatment of AKI could represent an important instrument for inducing a modulation of the immune response and inflammation, fundamental for a faster recovery of renal function.

In agreement with these observations and differently from what was observed in rats treated with FMhMSCs, electron microscopy did not evidence inflammatory responses in the group of rats treated with HB-FMhMSCs (Fig. 10). A statistically significant increase in antiinflammatory molecules was one of the elements characterizing the preliminary in vitro steps of this study. These results indicate that administration of mesenchymal stem cells, particularly when preconditioned with $\mathrm{HB}$, could help to reduce levels of inflammation, which is now recognized to be a very important factor in the pathophysiology of ischemic AKI (5).

Although rats administered with HB-untreated and treated MSCs were characterized by a similar recovery of renal function, we observed differences relative to their ability to secrete prosurvival and differentiating growth factors. Experimental in vitro procedures evidenced a controversial direct effect of HB-treated FMhMSCs, characterized by an increment of several factors (e.g., follistatin and HGF), but not by an influence on VEGF secretion. In vivo studies, instead, showed that there is a 10 times increase in VEGF levels in MSC-HB rats, compared either to controls and the MSC group. These results suggest that HB-treated FMhMSC effect is due not only to their secretive ability, but also to an indirect stimulation of VEGF release, probably from in situ cells. It is worth noting that VEGF appears to be one of the most important mediators of renoprotection induced by FMhMSCs (39). Cells treated with $\mathrm{HB}$, moreover, secreted a certain number of angiogenic factors (e.g., follistatin, HGF, G-CSF, PECAM-1, leptin), that could contribute to healing the injured kidney (Fig. 3). Accordingly, at the end of the experimental procedure, ultrastructural studies revealed not only a complete recovery of tubular structures but also capillary neoformation, as depicted in Figures 10 and 11. These features were evidenced only in animals that were administered with stem cells, both untreated and pretreated with $\mathrm{HB}$.

Furthermore, these factors own important properties besides promoting angiogenesis. For example, follistatin is also known as an inhibitor of inflammation (19); HGF is one of the most important antiapoptotic cytokines and it is thought to inhibit fibrosis (47); PECAM-1 release is able to induce tissue repair and vessel reconstruction, beyond being a marker for endothelial differentiation (46). The release of such factors could deeply influence the kidney milieu, thus promoting the formation of new vessels to replace the damaged ones, lowering the inflammation status, protecting renal cells from apoptosis, and restoring cytoplasmatic structures, all features that ultrastructural studies documented.

We were not able to detect large differences between the effects of normal FMhMSCs and HB-treated cells in renal recovery, probably because the damage is prevalently functional with a mild organic injury, as confirmed by histological features. This was proven by the evidence that damage was reversible per se, because untreated rats show full functional recovery just after 7 days from experimental procedures, with no need of extracorporeal renal substitution techniques. Presumably, in a setting of acute tubular necrosis (ATN), the effect of differentiating molecules would be to induce tissue repair more rapidly. This eventuality needs to be verified by different experimental models.

Microscopy analyses showed a persisting and predominantly tubular damage in every group of rats, despite a full recovery of renal function. This result proves how renal function restoration anticipates complete tissue repair and confirms that clinical parameters such as creatinine, urea, and FE-Na are not accurate enough in detecting mild and premature renal impairment, so that it is necessary to find more precise methods to determine the presence and amount of renal damage $(16,40)$.

In summary, we demonstrated that administered human FMhMSCs can improve renal function after I/R damage in a model of wild-type rat. This is confirmed by the analysis of clinical parameters and morphological aspects of injured kidneys. Our hypothesis is that the effect of FMhMSCs could be mediated by the secretion of factors, such as HGF and G-CSF, that stimulate recovery and it seems to influence the enhanced clinical and functional trends. We also demonstrated that differentiating agents are able to induce an increased reactivity of FMhMSCs or a greater secretion of factors that stimulate differentiation. Pretreatment of cells with hyaluronan esters could enhance FMhMSC properties in stimulating angiogenesis and vascular regeneration and could potentially be useful in treatment of ATN.

There are still contrasting evidences on the contribution of FMhMSCs to the restoration of renal damage. Some studies support the hypothesis for proliferation and transdifferentiation of FMhMSCs at the site of damage $(30,45)$. On the contrary, many works disagree and indicate that extrarenal cells have little or no effect at all. An important work by Humphreys and colleagues (12) reported that neither extrarenal cells nor medullary cells contribute to tissue repair by replacing lost cells in kidney cortex. It is possible that restoration is mediated by cortex residential progenitor cells $(21,31)$.

Our hypothesis, however, is strongly supported by several works: for example, Tögel et al. demonstrated that administration of FMhMSCs could improve kidney function after I/R damage and found no clue of transdifferentiation of cells; a paracrine effect was suggested 
by altered levels of several cytokines, as well as higher proliferative and lower apoptotic rates, lower inflammation indexes, and a minor extent of kidney damage (37).

In conclusion, in our study FMhMSCs did not structurally contribute to tissue repair as expected. These cells, especially if treated with differentiating agents, may serve as a reservoir of factors that act on kidney environment, thus stimulating either recovery of damaged cells or potential residential stem cells to proliferate and differentiate, determining recovery of tubular epithelial cells with evidence of neoangiogenesis. The use of $\mathrm{HB}$ on FMhMSCs before administration in rats seemed to induce an enhanced anti-inflammatory effect. ACKNOWLEDGMENTS: Supported in part by "Fondazione del Monte di Bologna e Ravenna," Project "Il rigetto a medio e lungo termine nei trapianti d'organo"-main investigator: Professor Sergio Stefoni.

\section{REFERENCES}

1. Aggarwal, S.; Pittenger, M. F. Human mesenchymal stem cells modulate allogenic immune cell response. Blood 19: 1815-1822; 2005.

2. Bartholomew, A.; Sturgeon, C.; Siatskas, M.; Ferrer, K.; McIntosh, K.; Patil, S.; Hardy, W.; Devine, S.; Ucker, D.; Deans, R.; Moseley, A.; Hoffman, R. Mesenchymal stem cells suppress lymphocyte proliferation in vitro and prolong skin graft survival in vivo. Exp. Hematol. 30:42-48; 2002 .

3. Bi, B.; Schmitt, R.; Israilova, M.; Nishio, H.; Cantley, L. G. Stromal cells protect against acute tubular injury via an endocrine effect. J. Am. Soc. Nephrol. 18:2486-2496; 2007.

4. Blandini, F.; Cova, L.; Armentero, M.; Zennaro, E.; Levandis, G.; Bossolasco, P.; Calzarossa, C.; Mellone, M.; Giuseppe, B.; Deliliers, G. L.; Polli, E.; Nappi, G.; Silani, V. Transplantation of undifferentiated human mesenchymal stem cells protects against 6-hydroxydopamine neurotoxicity in the rat. Cell Transplant. 19(2):203-217; 2010.

5. Bonventre, J. V.; Zuk, A. Ischemic acute renal failure: An inflammatory disease? Kidney Int. 66:480-485; 2004.

6. Chen, L. B.; Jiang, X. B.; Yang, L. Differentiation of rat marrow mesenchymal stem cells into pancreatic islet betacells. World J. Gastroenterol. 10(20):3016-3020; 2004.

7. Chhabra, P.; Brayman, K. L. The use of stem cells in kidney disease. Curr. Opin. Organ Transplant. 14:72-78; 2009.

8. Frühbeck, G. Intracellular signalling pathways activated by leptin. Biochem. J. 393:7-20; 2006.

9. Geffner, L. F.; Santacruz, P.; Izurieta, M.; Flor, L.; Maldonado, B.; Auad, A. H.; Montenegro, X.; Gonzales, R.; Silva, F. Administration of autologous bone marrow stem cells into spinal cord injury patients via multiple routes is safe and improves their quality of life: Comprehensive case studies. Cell Transplant. 17(12):1277-1293; 2008.

10. Heldin, C. H.; Westermark, B. Mechanism of action and in vivo role of platelet-derived growth factor. Physiol. Rev. 79(4):1283-1316; 1999.

11. Herrera, M. B.; Bussolati, B.; Bruno, S.; Morando, L.; Mauriello-Romanazzi, G.; Sanavio, F.; Stamenkovic, I.; Biancone, L.; Camussi, G. Exogenous mesenchymal stem cells localize to the kidney by means of CD44 following acute tubular injury. Kidney Int. 72(4):430-441; 2007.
12. Humphreys, B. D.; Bonventre, J. V. Mesenchymal stem cells in acute kidney injury. Annu. Rev. Med. 59:311325; 2008.

13. In't Anker, P. S.; Scherjon, S. A.; Kleijburg-van der Keur, C.; de Groot-Swings, G. M.; Claas, F. H.; Fibbe, W. E.; Kanhai, H. H. Isolation of mesenchymal stem cells of fetal or maternal origin from human placenta. Stem Cells 22(7): $1338-1345 ; 2004$

14. Jiang, X. X.; Zhang, Y.; Liu, B.; Zhang, S. X.; Wu, Y.; Yu, X. D.; Mao, N. Human mesenchymal stem cells inhibit differentiation and function of monocyte-derived dendritic cells. Blood 105(10):4120-4126; 2005.

15. Karpinski, J.; Lajoie, G.; Cattran, D.; Fenton, S.; Zaltzman, J.; Cardella, C.; Cole, E. Outcome of kidney transplantation from high-risk donors is determined by both structure and function. Transplantation 67(8):1162-1167; 1999.

16. Kellum, J. A. Acute kidney injury. Crit. Care Med. 36(Suppl. 4):S141-S145; 2008.

17. Klyushnenkova, E.; Mosca, J. D.; Zernetkina, V.; Majumdar, M. K.; Beggs, K. J.; Simonetti, D. W.; Deans, R. J.; McIntosh, K. R. T cell responses to allogeneic human mesenchymal stem cells: Immunogenicity, tolerance, and suppression. J. Biomed. Sci. 12:47-57; 2005.

18. Knudson, W.; Chow, G.; Knudson, C. B. CD44-mediated uptake and degradation of hyaluronan. Matrix Biol. 21(1): 15-23; 2002.

19. Kozian, D. H.; Ziche, M.; Augustin, H. G. The activinbinding protein follistatin regulates autocrine endothelial cell activity and induces angiogenesis. Lab. Invest. 76(2): 267-276; 1997.

20. Lameire, N.; Van Biesen, W.; Vanholder, R. Acute renal failure. Lancet 365:417-430; 2005.

21. Lazzeri, E.; Crescioli, C.; Ronconi, E.; Mazzinghi, B.; Sagrinati, C.; Netti, G. S.; Angelotti, M. L.; Parente, E.; Ballerini, L.; Cosmi, L.; Maggi, L.; Gesualdo, L.; Rotondi, M.; Annunziato, F.; Maggi, E.; Lasagni, L.; Serio, M.; Romagnani, S.; Vannelli, G. B.; Romagnani, P. Regenerative potential of embryonic renal multipotent progenitors in acute renal failure. J. Am. Soc. Nephrol. 18:31283138; 2007.

22. Le Blanc, K.; Tammik, C.; Rosendahl, K.; Zetterberg, E.; Ringdén, O. HLA expression and immunologic properties of differentiated and undifferentiated mesenchymal stem cells. Exp. Hematol. 31:890-896; 2003.

23. Le Blanc, K.; Tammik, L.; Sundberg, B.; Haynesworth, S. E.; Ringdén, O. Mesenchymal stem cells inhibit and stimulate mixed lymphocyte cultures and mitogenic responses independently of the major histocompatibility complex. Scand. J. Immunol. 57:11-20; 2003.

24. Maeshima, A.; Zhang, Y. Q.; Nojima, Y.; Naruse, T.; Kojima, I. Involvement of the activin-follistatin system in tubular regeneration after renal ischemia in rats. J. Am. Soc. Nephrol. 12:1685-1695; 2001.

25. Marks, P. A.; Richon, V. M.; Rifkind, R. A. Histone deacetylase inhibitors: Inducers of differentiation or apoptosis of transformed cells. J. Natl. Cancer Inst. 92:12101216; 2000.

26. Matsumoto, K.; Nakamura, T. Hepatocyte growth factor: Renotropic role and potential therapeutics for renal diseases. Kidney Int. 59(6):2023-2038; 2001.

27. Metcalfe, W.; Simpson, M.; Khan, I. H.; Prescott, G. J.; Simpson, K.; Smith, W. C. S.; MacLeod, A. M. Acute renal failure requiring renal replacement therapy: Incidence and outcome. QJM 95:579-583; 2002.

28. Morigi, M.; Imberti, B.; Zoja, C.; Corna, D.; Tomasoni, 
S.; Abbate, M.; Rottoli, D.; Angioletti, S.; Benigni, A.; Perico, N.; Alison, M.; Remuzzi, G. Mesenchymal stem cells are renotropic, helping to repair the kidney and improve function in acute renal failure. J. Am. Soc. Nephrol. 15:1794-1804; 2004.

29. Poulsom, R.; Forbes, S. J.; Hodivala-Dilke, K.; Ryan, E.; Wyles, S.; Navaratnarasah, S.; Jeffery, R.; Hunt, T.; Alison, M.; Cook, T.; Pusey, C.; Wright, N. A. Bone marrow contributes to renal parenchymal turnover and regeneration. J. Pathol. 195:229-235; 2001.

30. Qian, H.; Yang, H.; Xu, W.; Yan, Y.; Chen, Q.; Zhu, W.; Cao, H.; Yin, Q.; Zhou, H.; Mao, F.; Chen, Y. Bone marrow mesenchymal stem cells ameliorate rat acute renal failure by differentiation into renal tubular epithelial-like cells. Int. J. Mol. Med. 22(3):325-332; 2008.

31. Sagrinati, C.; Netti, G. S.; Mazzinghi, B.; Lazzeri, E.; Liotta, F.; Frosali, F.; Ronconi, E.; Meini, C.; Gacci, M.; Squecco, R.; Carini, M.; Gesualdo, L.; Francini, F.; Maggi, E.; Annunziato, F.; Lasagni, L.; Serio, M.; Romagnani, S.; Romagnani, P. Isolation and characterization of multipotent progenitor cells from the Bowman's capsule of adult human kidneys. J. Am. Soc. Nephrol. 17: 2443-2456; 2006.

32. Snykers, S.; De Kock, J.; Rogiers, V.; Vanhaecke, T. In vitro differentiation of embryonic and adult stem cells into hepatocytes: State of the art. Stem Cells 27(3):577-605; 2009.

33. Sotiropoulou, P. A.; Perez, S. A.; Salagianni, M.; Baxevanis, C. N.; Papamichail, M. Characterization of the optimal culture conditions for clinical scale production of human mesenchymal stem cells. Stem Cells 24(2):462-471; 2006.

34. Stappenbeck, T. S.; Miyoshi, H. The role of stromal stem cells in tissue regeneration and wound repair. Science 324(5935):1666-1669; 2009.

35. Thomas, J.; Liu, F.; Link, D. C. Mechanisms of mobilization of hematopoietic progenitors with granulocyte colony-stimulating factor. Curr. Opin. Hematol. 9:183-189; 2002.

36. Thurston, G. Role of angiopoietins and tie receptor tyrosine kinases in angiogenesis and lymphangiogenesis. Cell Tissue Res. 314(1):61-68; 2003.

37. Tögel, F.; Hu, Z.; Weiss, K.; Isaac, J.; Lange, C.; Westenfelder, C. Administered mesenchymal stem cells protect against ischemic acute renal failure through differentiation-independent mechanisms. Am. J. Physiol. Renal Physiol. 289:F31-F42; 2005.

38. Tögel, F.; Weiss, K.; Yang, Y.; Hu, Z.; Zhang, P.; Westenfelder, C. Vasculotropic, paracrine actions of infused mesenchymal stem cells are important to the recovery from acute kidney injury. Am. J. Physiol. Renal Physiol. 292:F1626-F1635; 2007.

39. Tögel, F.; Zhang, P.; Hu, Z.; Westenfelder, C. VEGF is a mediator of the renoprotective effects of multipotent marrow stromal cells in acute kidney injury. J. Cell. Mol. Med. 13(8B):2109-2114; 2009.

40. Udy, A.; O'Donoghue, S.; D'Intini, V.; Healy, H.; Lipman, J. Point of care measurement of plasma creatinine in critically ill patients with acute kidney injury. Anaesthesia 64:403-407; 2009.
41. Ventura, C.; Cantoni, S.; Bianchi, F.; Lionetti, V.; Cavallini, C.; Scarlata, I.; Foroni, L.; Maioli, M.; Bonsi, L.; Alviano, F.; Fossati, V.; Bagnara, G. P.; Pasquinelli, G.; Recchia, F. A.; Perbellini, A. Hyaluronan mixed esters of butyric and retinoic acid drive cardiac and endothelial fate in term placenta human mesenchymal stem cells and enhance cardiac repair in infarcted rat hearts. J. Biol. Chem. 282(19):14243-14251; 2007.

42. Ventura, C.; Maioli, M.; Asara, Y.; Santoni, D.; Scarlata, I.; Cantoni, S.; Perbellini, A. Butyric and retinoic mixed esters of hyaluronan. J. Biol. Chem. 279:23574-23579; 2004.

43. Waikar, S. S.; Curhan, G. C.; Wald, R.; McCarthy, E. P.; Chertow, G. M. Declining mortality in patients with acute renal failure, 1988 to 2002. J. Am. Soc. Nephrol. 17: 1143-1150; 2006.

44. Wan, C. D.; Cheng, R.; Wang, H. B.; Liu, T. Immunomodulatory effects of mesenchymal stem cells derived from adipose tissues in a rat orthotopic liver transplantation model. Hepatobiliary Pancreat. Dis. Int. 7(1):29-33; 2008.

45. Wong, C. Y.; Cheong, S. K.; Mok, P. L.; Leong, C. F. Differentiation of human mesenchymal stem cells into mesangial cells in post-glomerular injury murine model. Pathology 40(1):51-57; 2008.

46. Woodfin, A.; Voisin, M. B.; Nourshargh, S. PECAM-1: A multi-functional molecule in inflammation and vascular biology. Arterioscler. Thromb. Vasc. Biol. 27(12):25142523; 2007.

47. Yang, J.; Liu, Y. Blockage of tubular epithelial to myofibroblast transition by hepatocyte growth factor prevents renal interstitial fibrosis. J. Am. Soc. Nephrol. 13:96-107; 2002.

48. Yen, B. L.; Huang, H. I.; Chien, C. C.; Jui, H. Y.; Ko, B. S.; Yao, M.; Shun, C. T.; Yen, M. L.; Lee, M. C.; Chen, Y. C. Isolation of multipotent cells from human term placenta. Stem Cells 23(1):3-9; 2005.

49. Yokoo, T.; Kawamura, T.; Kobayashi, E. Stem cells for kidney repair: Useful tool for acute renal failure? Kidney Int. 74(7):847-849; 2008.

50. Zhang, W.; Qin, C.; Zhou, Z. M. Mesenchymal stem cells modulate immune responses combined with cyclosporine in a rat renal transplantation model. Transplant. Proc. 39(10):3404-3408; 2007.

51. Zhang, X.; Jiao, C.; Zhao, S. Role of mesenchymal stem cells in immunological rejection of organ transplantation. Stem Cell Rev. 5(4):402-409; 2009.

52. Zhang, Y.; Woodward, V. K.; Shelton, J. M.; Richardson, J. A.; Zhou, X. J.; Link, D.; Kielar, M. L.; Jeyarajah, D. R.; Lu, C. Y. Ischemia-reperfusion induces G-CSF gene expression by renal medullary thick ascending limb cells in vivo and in vitro. Am. J. Physiol. Renal Physiol. 286(6):F1193-F1201; 2004.

53. Zhou, H. P.; Yi, D. H.; Yu, S. Q.; Sun, G. C.; Cui, Q.; Zhu, H. L.; Liu, J. C.; Zhang, J. Z.; Wu, T. J. Administration of donor-derived mesenchymal stem cells can prolong the survival of rat cardiac allograft. Transplant. Proc. 38(9):3046-3051; 2006. 